\title{
2 次の流出核の一計算手法について
}

$\begin{array}{crr}\text { 東京工業大学 } & \text { 日野 } & \text { 幹雄 } \\ \text { 同上 } & \text { ○灘岡 } & \text { 和夫 }\end{array}$

\section{I. 序 文}

降雨一流出系にわける非線形性の問題は，水文現象の確率性や非定常性などの問題とともに，重要な課題 であり，我が国の河川がおおむね強い非線形性を示すととから見ても，その機構の解明というととの持つ意 義にはきわめて大きいものがある。非線形流出系の解析は，てれまで, 貯留関数法などに代表されるような Parametric Hydrologyの他に, 客観的な方法として, いわゆるDynamic Hydrology とStochastic Hydrologyの 2 つ方向からなされている。流出現象の非線形性は，本質的には系の物理過程を支配する基 礎方程式が非線形であるととに起因しているので, 現象の解明という点からは, 前者の立場の方法論的な有 効性が予想されるが，実際には，基礎方程式が非線形であるというとと自体が解析上の大きな難点となるし， また, 流域系全体を包括的に理解するてとが困難であるという弱点もある。一方, 最近になって, 後者の立 場から, Wiener の確率的非線形理論（直交汎関数展開法 $)^{1)}$ を応用する試みがいくつかなされるようになっ ており ${ }^{2)}$ 非線形流出核を求めるてとにより，主として流出予測の面での予測精度の向上に成果を上げている。 しかし，てれらの試みは，およそ系をblack box としてとらえており，その点, 系の物理構造と流出の非線 形性とを結びつけることが困難であるし，また，データに依存した方法であるてとから一般性に欠けるとい う難点もある。(なお，Volterra Series あるいはWiener Seriesによる非線形流出系のデー夕解析法 にはいくつかの方法があり，てれについては前に論じた。”）

以上のように，てれらの二つの立場にはそれぞれに長所・欠点があるが，筆者らは，かねてより，てれら は統一されるべきものと考えている。そてで，ててでは，同じくWiener の理論を用いてではあるが，全く の確率論的手法で系をblack box と見立てて解析するのではなく，現象を支配する基锭方程式をもとにし， それとの関連から理論的に非線形核を導出する方法を提示するととを試み，その途中結果を報告した。

\section{II. 流出系への直交汎関数展開法の適用}

1）流出系のモデル

本論文で対象とする流出モデルは，以下に示すようなものである。

a . 降雨変動は, 定常確率過程でかつ正規ホワイトノイズとする。

b. 降雨は, 空間的に一様とする。

c . 流出は，表面流出のみを考え，基礎方程式としては，次の 2) に示すものを用いる。

d . パラメータは, 所与の定数であって, 時間不変。

e . 流域は，勾配一定の理想的流域を考元る。

上記 $\mathrm{a} \sim \mathrm{e}$ のうち, $\mathrm{a}, \mathrm{d}$ は, 直交汎関数展開法を適用するにあたって必要とされる条件である。（ただ し, パラメータは, 場所の関数であってもよいが，ててでは簡単のため空間的にも一定とした。）

2）基礎方程式

流体運動の基礎方程式としては，連続式(1)と，運動方程式の代わりに抵抗則(2)を用いるものとする。

$$
\begin{aligned}
& \frac{\partial \mathrm{h}}{\partial \mathrm{t}}+\frac{\partial \mathrm{q}}{\partial \mathrm{x}}=r(\mathrm{t}) \quad \text { (1) } \quad \mathrm{u}=\alpha \mathrm{h}^{\mathrm{m}} \\
& \mathrm{q}=\mathrm{uh} \quad \alpha \mathrm{h}^{\mathrm{m}+1}
\end{aligned}
$$

こに $\mathrm{h}(\mathrm{x}, \mathrm{t})$ : 水哚 $\mathrm{q}(\mathrm{x}, \mathrm{t})$ : 単位幅当りの流量 $r(\mathrm{t})$ : 降雨強度 $\mathrm{u}(\mathrm{x}, \mathrm{t}):$ 平均流速 $\alpha, \mathrm{m}:$ パラメーター

式(3)は，次の形で書く方が一般性を持つ。 


$$
\mathrm{q}=\mathrm{a} \mathrm{h}+\mathrm{b} \mathrm{h}^{2}+\mathrm{c} \mathrm{h}^{3}+\cdots \cdots
$$

従って，式(1)，(4)を1つにまとめると次式となる。

$$
\frac{\partial \mathrm{h}}{\partial \mathrm{t}}+\left(\mathrm{a}+2 \mathrm{bh}+3 \mathrm{c} \mathrm{h}^{2}+\cdots \cdots \cdots\right) \frac{\partial \mathrm{h}}{\partial \mathrm{x}}=r(\mathrm{t})
$$

※ててでは, 出力変数として水深 $\mathrm{h}$ をっている。周知のように，実際の単位図法などによる予測の問 題では出力変数に流量を用いているが, 本論文では, そのような, practicalな面での取り扱い云々 ではなく, 流出系の非線形性自体の内部構造を問題にしているので, ぞちらを出力変数にとるかとい うととは，2 次的な問題にすきない。そとで，乙てでは，実際の解析上での簡便さから比較して，水 梁 $\mathrm{h}$ とった方が, 式がやや簡単な形になるというととから, 出力変数として水梁 $\mathrm{h}$ を採用した。

3) 核関数に関する関係式の導出 まず，入力 $r(\mathrm{t})$ を次のようにおく。

$$
r(\mathrm{t})=\overline{\mathrm{R}}+\mathrm{R}(\mathrm{t})
$$

ここで， $\overline{\mathrm{R}}, \mathrm{R}(\mathrm{t})$ は式(7)(8)の様な性質を持つ変量である。

$$
\mathrm{E}[r(\mathrm{t})]=\overline{\mathrm{R}} \quad(7) \quad \mathrm{E}\left[\mathrm{R}\left(\mathrm{t}_{1}\right) \mathrm{R}\left(\mathrm{t}_{2}\right)\right]=\mathrm{k} \delta\left(\mathrm{t}_{1}-\mathrm{t}_{2}\right)
$$

$(\bar{R}, R(t)$ は，必ずしも $\bar{R} \gg R(t)$ であことを要しない。）

一方, 出力 $\mathrm{h}(\mathrm{x}, \mathrm{t})$ は, 入力 $r(\mathrm{t})$ 亿応じて定常な確率変量となるが，それを直交汎関数展開表示すると，

$$
\begin{aligned}
\mathrm{h}(\mathrm{x}, \mathrm{t})= & \mathrm{K}_{0}(\mathrm{x})+\int_{-\infty}^{\mathrm{t}} \mathrm{K}_{1}(\mathrm{x} ; \mathrm{t}-\sigma) \mathrm{R}_{\mathrm{I}}(\sigma) \mathrm{d} \sigma+\int_{-\infty}^{\mathrm{t}} \int_{-\infty}^{\mathrm{t}} \mathrm{K}_{2}\left(\mathrm{x} ; \mathrm{t}-\sigma_{1}, \mathrm{t}-\sigma_{2}\right) \mathrm{R}_{2}\left(\sigma_{1}, \sigma_{2}\right) \\
& \mathrm{d} \sigma_{1} \mathrm{~d} \sigma_{2}+\ldots \ldots \ldots . .
\end{aligned}
$$

ここに, $\mathrm{K}_{0}, \mathrm{~K}_{1}, \mathrm{~K}_{2} \cdots \cdots \cdots$ : 非確率的核関数で, 特に次の性質がある。

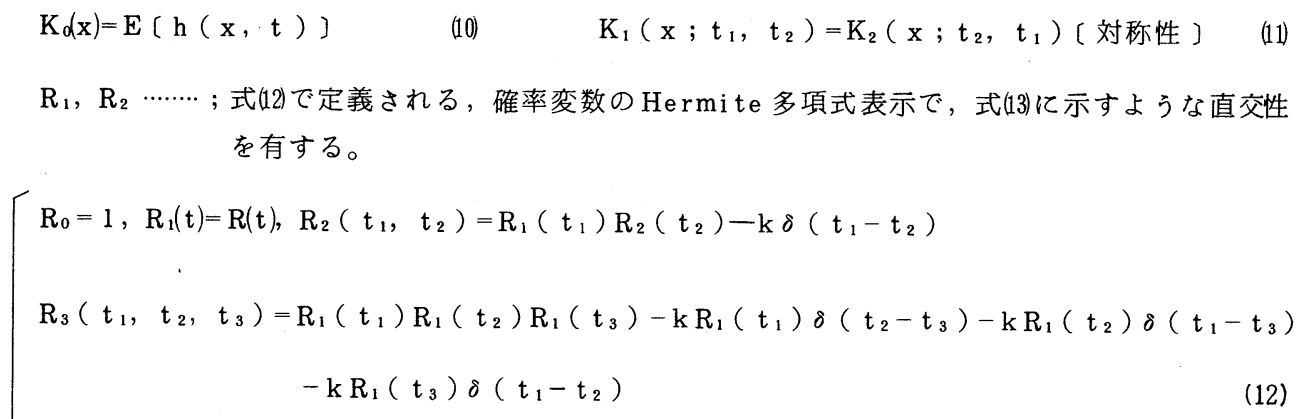

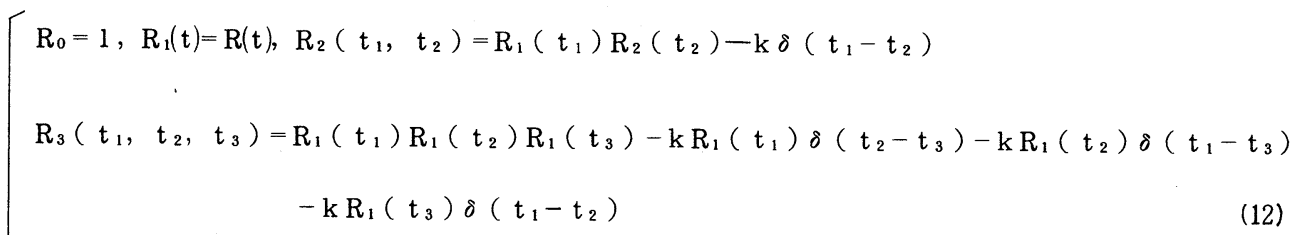

$R_{4}\left(t_{1}, t_{2}, t_{3}, t_{4}\right)=R_{1}\left(t_{1}\right) R_{1}\left(t_{2}\right) R_{1}\left(t_{3}\right) R_{1}\left(t_{4}\right)-k \Sigma R_{1}\left(t_{i}\right) R_{1}\left(t_{j}\right) \delta\left(t_{k}-t_{1}\right)$ $+k^{2} \Sigma \delta\left(t_{i}-t_{j}\right) \delta\left(t_{k}-t_{1}\right)$

$E\left[R_{m} \cdot R_{n}\right]=0 \quad ; m \neq n \quad(m, n=0,1,2, \cdots \cdots)$

式(12)で, summation $\Sigma$ は, i, j, k, l の全ての組み合せのうち，互いに他と異なる項を生成するものの全 ての和を意味する。

次に，抵抗則(4)は第 2 項までとるものとし，式(9)を 2 次の項までで打ち切り式(5)に代入する。そして式(13) の関係を利用して整理すると, 式(14)〜(16)に示すような, 核関数 $K_{0}, K_{1}, K_{2}$ を決定する連立微積分方程式を得 る。

$$
\left\lceil\{\mathrm{a}+2 \mathrm{bK}(\mathrm{x})\} \frac{\mathrm{d}}{\mathrm{dx}} \mathrm{K} d(\mathrm{x})+\mathrm{b} \mathrm{k} \int_{-\infty}^{\mathrm{t}} \frac{\partial}{\partial \mathrm{x}}\left\{\mathrm{K}_{1}(\mathrm{x} ; \mathrm{t}-\tau)\right\}^{2} \mathrm{~d} \tau+2 \mathrm{bk} \mathrm{k}^{2} \int_{-\infty}^{\mathrm{t}} \frac{\partial}{\partial \mathrm{x}}\left\{\mathrm{K}_{2}\left(\mathrm{x} ; \mathrm{t}-\tau_{1}, \mathrm{t}-\tau_{2}\right)\right\}^{2} \mathrm{~d} \tau_{1} d \tau_{2}\right.
$$


$\left.\mathrm{K}_{1}(\mathrm{x} ; 0) \delta(\mathrm{t}-\tau)+\frac{\partial \mathrm{K}_{1}(\mathrm{x} ; \mathrm{t}-\tau)}{\partial \mathrm{t}}+\mathrm{a} \frac{\partial \mathrm{K}_{1}(\mathrm{x} ; \mathrm{t}-\tau)}{\partial \mathrm{x}}+2 \mathrm{~b} \frac{\partial}{\partial \mathrm{x}}\{\mathrm{K} d \mathrm{x}) \mathrm{K}(\mathrm{x} ; \mathrm{t}-\tau)\right\}$

$$
+4 b k \int_{-\infty}^{t} \frac{\partial}{\partial x}\left\{K_{1}(x ; t-\tau) K_{2}(x ; t-\tau, t-\sigma)\right\} d \sigma=\delta(t-\tau)
$$

$\mathrm{K}_{2}\left(\mathrm{x} ; 0, \mathrm{t}-\tau_{2}\right) \delta\left(\mathrm{t}-\tau_{1}\right)+\mathrm{K}_{2}\left(\mathrm{x} ; \mathrm{t}-\tau_{1}, 0\right) \delta\left(\mathrm{t}-\tau_{2}\right)+\frac{\partial \mathrm{K}_{2}\left(\mathrm{x} ; \mathrm{t}-\tau_{1}, \mathrm{t}-\tau_{2}\right)}{\partial \mathrm{t}}$

$$
\begin{aligned}
& \left.+\mathrm{a} \frac{\partial \mathrm{K}_{2}\left(\mathrm{x} ; \mathrm{t}-\tau_{1}, \mathrm{t}-\tau_{2}\right)}{\partial \mathrm{x}}+2 \mathrm{~b} \frac{\partial}{\partial \mathrm{x}}\{\mathrm{K} d \mathrm{x}) \mathrm{K}_{2}\left(\mathrm{x} ; \mathrm{t}-\tau_{1}, \mathrm{t}-\tau_{2}\right)\right\}+\mathrm{b} \frac{\partial}{\partial \mathrm{x}}\left\{\mathrm{K}_{1}\left(\mathrm{x} ; \mathrm{t}-\tau_{1}\right)\right. \\
& \left.\mathrm{K}_{1}\left(\mathrm{x} ; \mathrm{t}-\tau_{2}\right)\right\}+4 \mathrm{bk} \int_{-\infty}^{\mathrm{t}} \frac{\partial}{\partial \mathrm{x}}\left\{\mathrm{K}_{2}\left(\mathrm{x} ; \mathrm{t}-\sigma, \mathrm{t}-\tau_{1}\right) \mathrm{K}_{2}\left(\mathrm{x} ; \mathrm{t}-\sigma, \mathrm{t}-\tau_{2}\right)\right\} \mathrm{d} \sigma=0
\end{aligned}
$$

式(14)〜(16)によれば以下のようなととが分かる。

1）核の決定に関連してくるパラメーターは，抵抗則の中のパラメーター $\mathrm{a} ， \mathrm{~b}$ と，入力 $r(\mathrm{t})$ の有する 情報 $\bar{R}, \mathrm{k}$ 值とである。( こてで， $\mathrm{k}$ 值は，式(8)の定義を見ても分かるように， $\mathrm{k}=\int_{-\infty}^{\infty} E[R(t) R(t-\sigma)]$ $\mathrm{d} \sigma=\int_{-\infty}^{\infty} \mathrm{C}{ }_{\mathrm{ii}}(\sigma) \mathrm{d} \sigma て ゙$ あ, 従ってそれは, $\mathrm{R}(\mathrm{t})$ の変動レベルの大きさを表わしている。) 従って, 応答 㤥を, その流域の特性のみによって決定されるものとするのは問題があると言える。

ii）非線形性を有する系での各次の応答核は，それぞれ独立に決定されず，互いに他との連関を持って いる。換言すれば, 各次の応答核間には interactionが存在する。しかし, 線形の場合には, てれら の interactionはなくなり， $\mathrm{K}_{0}, \mathrm{~K}_{1}$ は独立に決定される。

\section{III. 流出核の具体的算定}

前節で導出した, 式(14)〜(16)は, 非線形の連立微積分方程式であり, てれを, 何らの近似も行わずに解くて とは困難で, 最終的には電子計算機による数值解に頼らざるを得ない。しかし, 直接, 数值的に解くには, 式(15)(16)が 8 関数を含んでいるととから問題がある。筆者らは, その点を避ける一方法として, 式(14) (16)を周 波数空間に写像して解く方法を既に提示している。本論文では, その方法の欠点を補い(後述), また, 先 に述べた問題点を避け得る別の方法として，Galerkin法によって解く方法を示した。

なお，ててで得られる数值解は，個々のヶースに対する普通の意味の数值解でなく，現象についての一般 的解であるというととを強調しておく。

1) Galerkin法の適用

流出核を次のように展開表示する。

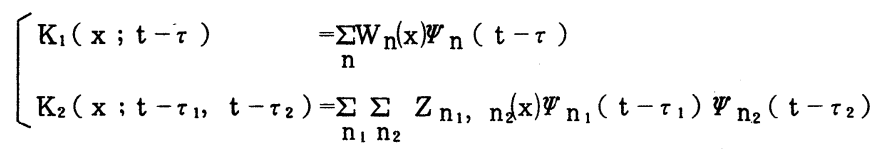

とてに,

$$
\Psi_{\mathrm{n}}(\mathrm{t}-\tau)=\operatorname{EXP}\left[-\frac{1}{2}(\mathrm{t}-\tau)\right] \mathrm{L}_{\mathrm{n}}(\mathrm{t}-\tau) \quad \mathrm{L}_{\mathrm{n}} ; \text { Laguerre 多項式 }
$$

(18)

こてで, 直交関数系としてLaguerre 多項式を用いたのは, この関数が $(0, \infty)$ にわいて定義されていて

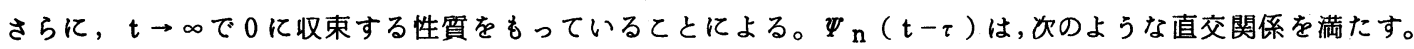

$$
\int_{-\infty}^{\mathrm{t}} \Psi_{\mathrm{m}}(\mathrm{t}-\tau) \Psi_{\mathrm{n}}(\mathrm{t}-\tau) \mathrm{d} \tau=\delta \mathrm{n}, \mathrm{m}
$$

式(17)を式(14) (16)に代入し，式(199の関係を用いて整理すると次式を得る。

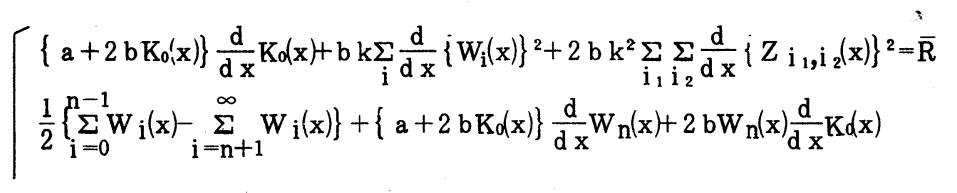




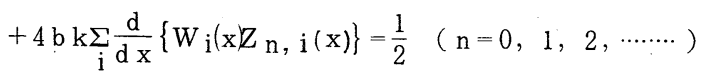

$$
\begin{aligned}
& \frac{1}{2}\left\{\sum_{\mathrm{i}=0}^{\mathrm{n}_{2}-1} \mathrm{Z}_{\mathrm{n}_{1}}, \quad \mathrm{i}(\mathrm{x})-\sum_{\mathrm{i}=\mathrm{n}_{2}+1}^{\infty} \mathrm{Z}_{\mathrm{n}_{1}}, \quad \mathrm{i}(\mathrm{x})+\sum_{\mathrm{i}=0}^{\mathrm{n}_{1}-1} \mathrm{Z}_{\mathrm{i}}, \mathrm{n}_{2}(\mathrm{x})-\sum_{\mathrm{i}=\mathrm{n}_{1}+1}^{\infty} \mathrm{Z}_{\mathrm{i}}, \mathrm{n}_{2}(\mathrm{x})\right\}+\{\mathrm{a}+2 \mathrm{bK}(\mathrm{x})\} \frac{\mathrm{d}}{\mathrm{dx}} \mathrm{Z}_{\mathrm{n}_{1},} \mathrm{n}_{2}(\mathrm{x}) \\
& +2 b Z_{n_{1}}, n_{2}(x) \frac{d}{d x} K_{0}(x)+b \frac{d}{d x}\left\{W_{n_{1}}\left(x W_{n_{2}}(x)\right\}+4 b k \sum_{i} \frac{x}{d x}\left\{Z_{n_{i}, n_{1}}(x) Z_{n_{i}, n_{2}}(x)\right\}=0\right. \\
& \left(\mathrm{n}_{1}, \mathrm{n}_{2}=0,1,2, \cdots \cdots\right)
\end{aligned}
$$

以上の手続きにより，式(14)〜(16)は，xを独立変数とする連立常微分方程式(20)〜(22)に帰着された。

2) Runge-Kutta-Gill 法による数值積分

式(20)〜(22)は，非線形連立常微方程式であるが，以下に示す手順によれば，Runge-Kutta-Gill法によっ て数值解を求めることが出来る。

式(21),(22)の方程式の数を有限な数 $\left(\mathrm{n}, \mathrm{n}_{1}, \mathrm{n}_{2} \leqq \mathrm{~m}\right)$ に打ち切り，マトリックス表示すると，

$$
\mathbb{A}(\mathrm{x}) \frac{\mathrm{d}}{\mathrm{d} x} \mathfrak{f}(\mathrm{x})=\mathbb{B} \cdot \mathfrak{f}(\mathrm{x})+\mathbf{d}
$$

とと

$\mathbb{A}(\mathrm{x}) ;(\mathrm{x})$ の值によって決まる係数マトリックス

B ; 係数マトリックス

$\mathbb{f}(\mathrm{x})=\left\{\mathrm{K}_{0}(\mathrm{x}), \mathrm{W}_{0}(\mathrm{x}), \cdots, \mathrm{W}_{\mathrm{m}}(\mathrm{x}), \mathrm{Z}_{0} \quad\left(\mathrm{x}, \cdots, \mathrm{Z}_{0, \mathrm{~m}}(\mathrm{x}), \mathrm{Z}_{\mathrm{l}, \mathrm{I}}(\mathrm{x}), \cdots \mathrm{Z}_{\mathrm{1}, \mathrm{m}}(\mathrm{x}) \cdots, \mathrm{Z}_{\mathrm{m}-1, \mathrm{~m}}(\mathrm{x}), \cdots, \mathrm{Z}_{\mathrm{m}, \mathrm{m}}(\mathrm{x})\right\}^{\mathrm{T}}\right.$

$$
\mathbb{d}=\{\bar{R}, \underbrace{\frac{1}{2}, \frac{1}{2}, \cdots, \frac{1}{2}}_{m+1}, \underbrace{0, \cdots, 0, \cdots, 0\}^{\mathbf{T}}}_{\frac{1}{2}(m+1)(m+2)}
$$

式(23)の両辺に左から $\mathbb{A}^{-1}(\mathrm{x})$ をかけると，

$$
\frac{\mathrm{d}}{\mathrm{d} \mathrm{x}} \mathbb{f}(\mathrm{x})=\mathbb{A}^{-1}(\mathrm{x})(\mathbb{B} \cdot \mathfrak{f}(\mathrm{x})+\mathbb{d})
$$

となるから, $\mathbb{A}(\mathrm{x})$ の逆行列の計算を連動させるととにより，上式は, Runge-Kutta-Gill 法によって数 值積分ができて， $\mathbb{f}(\mathrm{x})$ が求まるととになる。fig.-1に，計算を行うときの大まかなフローチャートを示す。

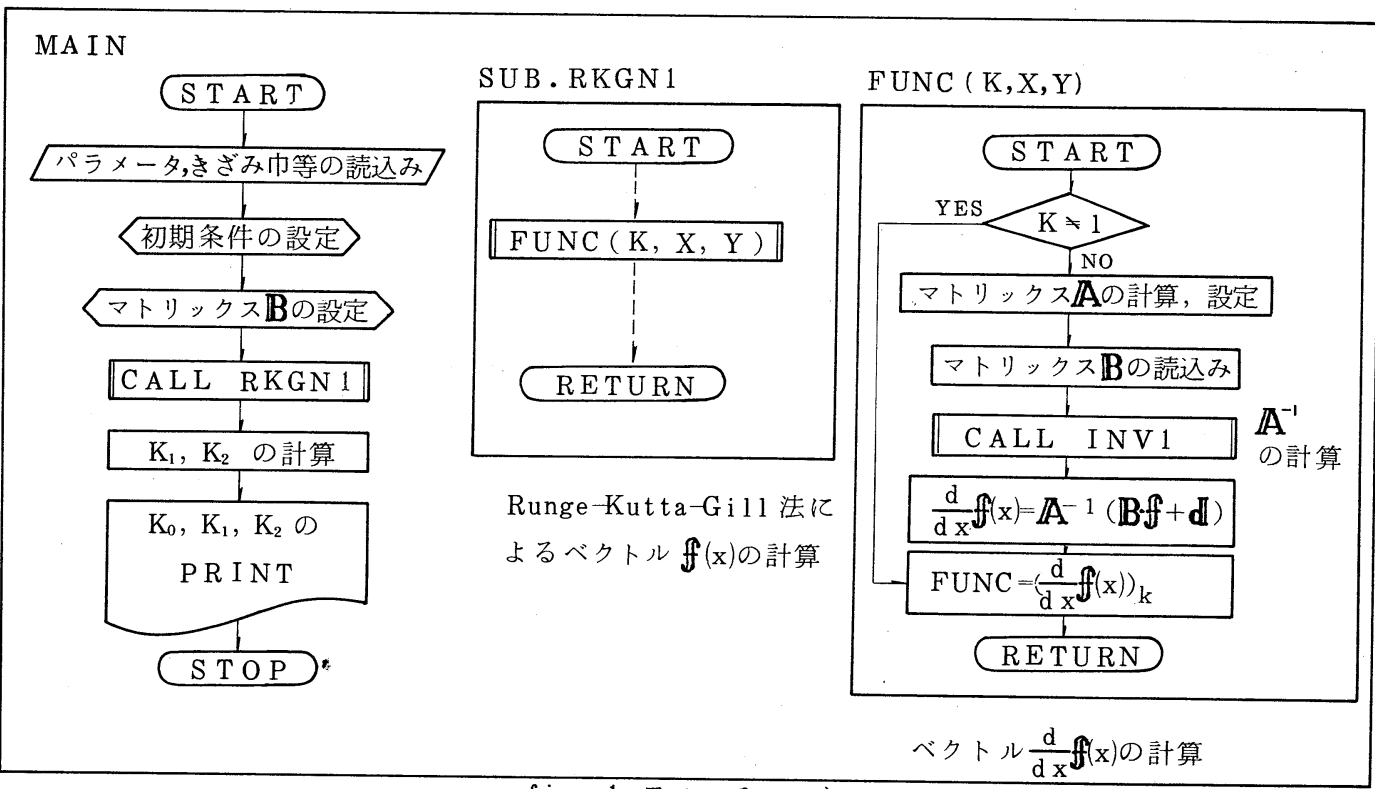

fig . 1 フローチャート 


\section{3) 計算例}

f ig. 2,3 亿，数值計算の途中結果の一例を示す。こて で，abの值は, Manningの平均流速公式でいえば, およそ, $\mathrm{n}=1.5, \mathrm{I}=1 / 10$ に対応するようなものを用いて いる。また, 初期条件としては, 上流端で水深がゼ口, すなわち，次式で示されるものを用いた。

$$
f(x)=\{0, \cdots, 0, \cdots, 0\}^{T} \quad(\text { at } \quad x=0)
$$

\section{IV 結 語}

本論文で示した方法により，流出系の基礎方程式から 理論的に非線形核を導出々来ることが分った。ててで用 いたWienerの確率的非線形理論は, 既に, 乱流の解析 にも適用されているが，そてではあまり良い結果が得ら れていない。それは, 流出の問題では2 2 次までの非線形 項をとればよいのに比べ，乱流では， energy cascade を表わすために項数を多くとらねばならないからである。 また, 式(14)〜(16)をGalerkin 法によって解く方法は, 計 算速度, 解の発散性, 記憶容量等の点で前に報告した方 法 $^{4)}$ より有利であると思われる。

\section{一参考文献—}

fig.2 線形核 $\left(K_{1}\right)$
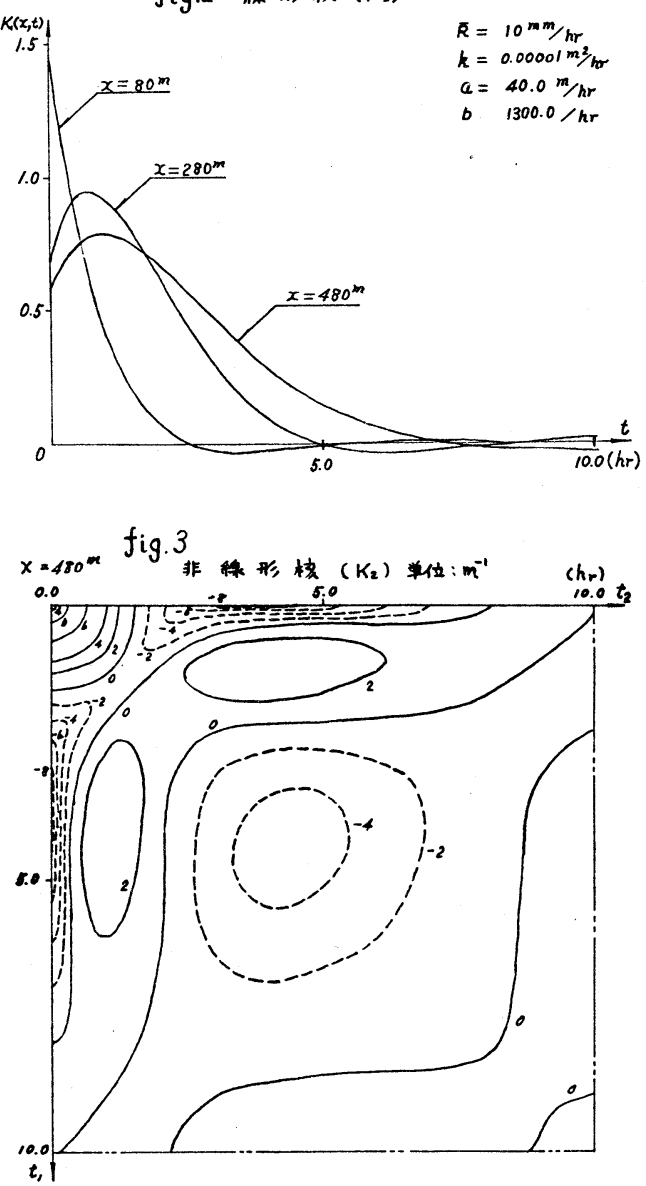

1) Wiener, N(1958):Nonlinear Problems in Random Theory, MIT Press

2）吉川秀夫・日野幹雄・鋤柄徹（1970）：降雨一流出系における非線形予測の研究, 東京工業大学土木工 学科研究報告, N6.8, p $97 \sim 104$

3）日野幹雄 (1975)：非線形流出解析および適応予測, 水工学シリーズ $75-\mathrm{A}-8$

4）日野・砂田・灘岡（1976）：非線形流出系の理論解析について, 第20回水理講演会論文集 